OPEN ACCESS

Edited by:

Guilherme Mariz De Oliveira Barra,

Universidade Federal de

Santa Catarina, Brazil

Reviewed by:

Peng-Cheng Ma,

University of Chinese Academy of Sciences (UCAS), China

Kenan Song,

Massachusetts Institute of Technology, United States

*Correspondence:

Juan J. Vilatela

juanjose.vilatela@imdea.org;

Marc Cretin

marc.cretin@umontpellier.fr

Specialty section:

This article was submitted

to Polymeric and

Composite Materials,

a section of the journal

Frontiers in Materials

Received: 22 December 2017

Accepted: 31 January 2018

Published: 21 February 2018

Citation:

Huong Le TX, Alemán B, Vilatela JJ,

Bechelany M and Cretin M (2018)

Enhanced Electro-Fenton

Mineralization of Acid Orange 7 Using a Carbon Nanotube

Fiber-Based Cathode.

Front. Mater. 5:9.

doi: 10.3389/fmats.2018.00009

\section{Enhanced Electro-Fenton Mineralization of Acid Orange 7 Using a Carbon Nanotube Fiber-Based Cathode}

\author{
Thi Xuan Huong Le' ${ }^{1}$, Belén Alemán², Juan J. Vilatela ${ }^{2 *}$, Mikhael Bechelany ${ }^{1}$ \\ and Marc Cretin ${ }^{1 *}$
}

${ }^{1}$ Institut Européen des membranes, IEM UMR-5635, ENSCM, CNRS, Univ. Montpellier, Montpellier, France, ${ }^{2}$ IMDEA Materials Institute, Madrid, Spain

A new cathodic material for electro-Fenton (EF) process was prepared based on a macroscopic fiber (CNTF) made of mm-long carbon nanotubes directly spun from the gas phase by floating catalyst CVD, on a carbon fiber (CF) substrate. CNTF@CF electrode is a highly graphitic material combining a high surface area $\left(\sim 260 \mathrm{~m}^{2} / \mathrm{g}\right)$ with high electrical conductivity and electrochemical stability. One kind of azo dye, acid orange 7 (AO7), was used as model bio-refractory pollutant to be treated at CNTF@CF cathode in acidic aqueous medium ( $\mathrm{pH}$ 3.0). The experimental results pointed out that $\mathrm{AO} 7$ and its organic intermediate compounds were totally mineralized by hydroxyl radical generated from Fenton reaction. In fact, $96.7 \%$ of the initial total organic carbon (TOC) was eliminated in $8 \mathrm{~h}$ of electrolysis by applying a current of $-25 \mathrm{~mA}$ and ferrous ions as catalyst at concentration of $0.2 \mathrm{mM}$. At the same electrolysis time, only $23.7 \%$ of TOC removal found on CF support which proved the high mineralization efficiency of new material thanks to CNTF deposition. The CNTF@CF cathode maintained stable its activity during five experimental cycles of EF setup. The results indicated that CNTF@CF material could be a potential choice for wastewater treatment containing bio-refractory by electrochemical advanced oxidation processes.

Keywords: azo dye, carbon nanotube fiber, electro-Fenton process, stability, mineralization

\section{INTRODUCTION}

Urban industrial operation has long been identified as a major cause of environmental contaminations through atmospheric deposition and wastewater discharge. The wastewater containing persistent organic pollutants (POPs) is always a dangerous threat for living environment because of their high toxicity and difficulty to treat completely by using normal physical chemistry methods. Advanced oxidation processes (AOPs) are widely investigated for the removal of recalcitrant organic pollutants from wastewater. The completely destruction of these refractory molecules without dangerous intermediate products is vital and becomes one major concern in this area. Over the past decade, the AOPs have attracted increasing interest as promising powerful methods for efficiently removing dyes from water. AOPs are environmentally friendly chemical, photochemical, or electrochemical methods sharing the common feature of the in situ production of hydroxyl radicals $(\mathrm{OH})$ as their main oxidizing agent. One of the most popular chemical AOPs is the Fenton 
method, where a mixture of $\mathrm{Fe}^{2+}$ and $\mathrm{H}_{2} \mathrm{O}_{2}$ (Fenton's reagent) is used to degrade organic compounds (Brillas et al., 2009):

$$
\begin{gathered}
\mathrm{Fe}^{2+}+\mathrm{H}_{2} \mathrm{O}_{2}+\mathrm{H}^{+} \rightarrow \mathrm{Fe}^{3+}+\cdot \mathrm{OH}+\mathrm{H}_{2} \mathrm{O} \\
\mathrm{RH}+{ }^{\bullet} \mathrm{OH} \rightarrow \text { oxidation products. }
\end{gathered}
$$

To avoid using chemical reactants, $\mathrm{H}_{2} \mathrm{O}_{2}$ can be produced by direct electro-reduction of dissolved $\mathrm{O}_{2}$ on graphite-based electrode:

$$
\mathrm{O}_{2}+2 \mathrm{H}^{+}+2 \mathrm{e}^{-} \rightarrow \mathrm{H}_{2} \mathrm{O}_{2} .
$$

When combined with $\mathrm{Fe}^{2+}$ to produce hydroxyl radicals, the method [called electro-Fenton (EF)] is more efficient than the basic Fenton process and easier to manage (Brillas et al., 2009). The EF process using carbon and graphite felt cathodes have been applied to remove successfully many different kinds of POPs including dye pollutants (Panizza and Oturan, 2011), pharmaceutical compounds (Sirés et al., 2007), herbicides and pesticides (Aaron and Oturan, 2001). In addition, the friendly environmental feature of EF treatment is also proved when it can degrade efficiently the very toxic initial contaminants to non-toxic compounds like $\mathrm{CO}_{2}, \mathrm{H}_{2} \mathrm{O}$, or short-chain carboxylic acids (Le et al., 2016b, 2017).

In EF process, carbonaceous materials are usually used as cathode, such as reticulated vitreous carbon (Martínez and Uribe, 2012), carbon sponge (Özcan et al., 2008), carbon felt (Le et al., 2015a), three-dimensional graphite system (Wang et al., 2008), or activated carbon fiber (Wang et al., 2005). To improve the performance (i.e., the conductivity, the surface area and the hydrophilicity) of cathodic electrode, many modification ways have been successfully applied (Le et al., 2015a). Graphene modification could enhance significantly the electrochemical property of commercial carbon felt (Le et al., 2015b). There was a 10 times higher peak area current to the redox probe $\left[\mathrm{Fe}(\mathrm{CN})_{6}\right]^{3-} /\left[\mathrm{Fe}(\mathrm{CN})_{6}\right]^{4-}$ on modified cathode and $2.17 \Omega$ charge-transfer resistance lower than that obtained on raw CF. Consequently, total organic carbon (TOC) removal of $\mathrm{AO} 7$ after $2 \mathrm{~h}$ treatment found at $73.9 \%$ for graphene-CF instead of $55.6 \%$ at non-modified one. By thermal treatment of CF under feeding of nitrogen gas flow mixed of $1 \%$ oxygen, a porous carbonaceous cathode was synthesized for the elimination of pharmaceutical pollutant, acetaminophen by EF treatment. The specific surface area increased considerably at $64 \mathrm{~m}^{2} \mathrm{~g}^{-1}$ that was nearly 700 times higher than raw CF (Le et al., 2016a). The search for suitable material having outstanding electrochemical properties is always a big challenge of EF technology. To contribute to the enrichment of cathodic materials, in this study, we fabricated a new cathode based on carbon nanotube fiber (CNTF) directly spun from the gas phase by floating catalyst CVD and deposited on a carbon fiber (CF) substrate. The millimeter long CNTs produced by this floating catalyst CVD process at high temperature $\left(1,250^{\circ} \mathrm{C}\right)$ (Li et al., 2004) leads to the formation of an elastic CNT aerogel than can be withdrawn and directly spun continuously into a macroscopic fiber that exploits CNTs unique mechanical, thermal, and electrical properties. Macroscopic CNT fibers have high-performance mechanical properties (specific tensile strength of $1.5 \mathrm{GPa} / \mathrm{SG}$, modulus of $60 \mathrm{GPa} / \mathrm{SG}$, and toughness of $80 \mathrm{~J} / \mathrm{g})$, high conductivity $\left(3.5 \times 10^{5} \mathrm{~S} / \mathrm{m}\right)$, and high surface area $\left(260 \mathrm{~m}^{2} / \mathrm{g}\right)$ and are thus ideal electrodes and current collectors for various devices (Vilatela and Marcilla, 2015). The CNTF@CF later was applied as cathode for mineralization of $\mathrm{AO} 7$ in aqueous medium by EF process by applying constant current and using soluble iron as catalyst.

\section{EXPERIMENTAL}

\section{Chemicals}

AO7 (Orange II sodium salt) was purchased from Sigma-Aldrich. Sodium sulfate (anhydrous, 99.0-100.5\%), sulfuric acid (ACS reagent, 95.0-98.0\%), and iron (II) sulfate heptahydrate (99\%) were used without any purification.

\section{Preparation of CNTF@CF Cathode}

Carbon nanotube fiber was synthesized by direct spinning of millimeters long CNTs from the gas phase by floating catalyst CVD (Li et al., 2004) at $1,250^{\circ} \mathrm{C}$ under hydrogen flow using butanol as $\mathrm{C}$ source, ferrocene as Fe catalyst, and thiophene as S-containing promoter. The precursors wt.\% ratio was adjusted (97.7 wt.\% of butanol, 0.8 wt.\% of ferrocene, and 1.5 wt.\% of thiophene) to synthesize carbon nanotubes with few layers $(<5)$ with an average diameter of $5 \mathrm{~nm}$ (Reguero et al., 2014). These large-diameter few-layer CNTs tend to collapse into graphitic ribbons. The fibers were spun for $10 \mathrm{~min}$ and collected as a film directly integrated on a carbon fiber (CF) substrate and condensed with acetone to enhance the adhesion between the two materials.

\section{Characterization}

Morphological characterization of the CNTF@CF cathode was carried out using a dual beam with field-emission scanning electron microscope FIB-FEGSEM, Helios NanoLab 600i FEI at $15 \mathrm{keV}$. Raman spectroscopy was performed by a Renishaw PLC spectrometer with $532 \mathrm{~nm}$ wavelength laser excitation and $1.6 \mu \mathrm{m}$ spot size with a laser power of $3 \mathrm{~mW}$. X-ray photoelectron spectroscopy (XPS) data were collected in a Thermo Scientific K-Alpha X-ray Photoelectron Spectrometer system with a photon energy of $1,486.68 \mathrm{eV}$. The deconvolution shown is fitted by Gaussian/Lorentzian peak shapes and Shirley background profile subtraction.

\section{Experimental EF System}

The experiment was performed in a cylindrical undivided and open electrochemical cell containing $100 \mathrm{~mL}$ solution. A palate $\mathrm{Ni} / \mathrm{Ti}$ grid with $5 \mathrm{~cm}$ height $\times 2 \mathrm{~cm}$ width was used as anode. A small surface area of cathode $(4 \mathrm{~cm} \times 2 \mathrm{~cm})$ was submerged in electrolysis solution, and placed parallel to anode with the distance of $3 \mathrm{~cm}$. The aqueous solution contained $\mathrm{Na}_{2} \mathrm{SO}_{4}$ $(50 \mathrm{mM})$ as supporting electrolyte and $0.2 \mathrm{mM} \mathrm{Fe}^{2+}$ as catalyst as the optimal concentration catalyst for EF experiment which was investigated in our previous study (Le et al., 2016a). The $\mathrm{pH}$ was adjusted at 3.0 as the optimum $\mathrm{pH}$ value in EF process (Özcan et al., 2009) by $\mathrm{H}_{2} \mathrm{SO}_{4}(1 \mathrm{M}$ ) and measured by a $\mathrm{pH}$ meter (Radiometer Analytical). The pure oxygen with purity of $99.9 \%$ 
was bubbled into the treated solution near the cathode surface 15 min before and kept continuously during the electrolysis. To increase the mass transport and also ensure the necessary concentration of dissolved oxygen for production $\mathrm{H}_{2} \mathrm{O}_{2}$ at cathode, the solution was vigorously stirred by a magnetic equipment with 800 rounds/min at room temperature $\left(\sim 25^{\circ} \mathrm{C}\right)$. A constant current was unendingly applied at $-25 \mathrm{~mA}$ using a galvanostatic mode (Lambda Electronique, USA) power supply. The mineralization efficiency was monitored by measuring the TOC removal from initial period to several treatment times at 2 , 4,6 , and $8 \mathrm{~h}$, respectively. The TOC analysis was conducted with a TOC-L CSH/CSN Shimadzu (Japan) analyzer. The values were trial measured with an accuracy of $\pm 1 \%$ by automatic injection of $50 \mu \mathrm{L}$ aliquots. Before the TOC measurement, the samples were filtered with $0.2-\mu \mathrm{m}$ filters purchased from Whatman to eliminate all of possible precipitation or fiber coming from cathode.

\section{RESULTS AND DISCUSSION}

\section{Characterization of CNTF@CF Cathode}

The carbon nanotube fiber electrode has a large porosity arising from the imperfect packing of nanotube bundles (Yue et al., 2017), as shown in Figure 1A. Yet, the CNT are also associated in long bundles, forming a highly conducting network of crystalline domains. Each nanotube bundle is made of various $\mathrm{mm}$-long CNTs in turbostratic arrangement. The constituent CNTs have few layers (Figure 1A, inset) and a highly graphitic structure in terms of $\mathrm{sp}^{2}$ conjugation, as observed by Raman and XPS spectroscopy (Figures 1B,C). The Raman spectrum of CNTF@ CF cathode (Figure 1B) shows the characteristic features of fewlayer CNTs consisting of the absence of radial breathing modes at $100-300 \mathrm{~cm}^{-1}$, a G band at $\sim 1.350 \mathrm{~cm}^{-1}$, D band at $\sim 1,350 \mathrm{~cm}^{-1}$, and the rest of overtone modes in the range of 2,400-3,000 $\mathrm{cm}^{-1}$ (Dresselhaus et al., 2005). The low intensity ratio of D to $\mathrm{G}$ bands $\left(\mathrm{I}_{\mathrm{D}} / \mathrm{I}_{\mathrm{G}}\right)$ around 0.15 indicates the high graphitic nature ( $\mathrm{G}$ band) of these CNTs with respect to the amount of defects ( $\mathrm{D}$ band) as, i.e., carbonaceous impurities with $\mathrm{sp}^{3}$ bonding or broken $\mathrm{sp}^{2}$ bonds. $2 \mathrm{D}$ band position around $2,700 \mathrm{~cm}^{-1}$ also confirms the multi-wall character of the nanotubes within the fiber (Reguero et al., 2014). On the other hand, XPS spectroscopy is a more surface sensitive technique compared to Raman spectroscopy therefore C1s core level emission (Figure 1C) not only presents the components related to pure graphitic nanotube structure as $\mathrm{C} \mathrm{sp}{ }^{2}$ at $284.5 \mathrm{eV}(\mathrm{C}=\mathrm{C})$ and $\pi-\pi^{\star}$ band at $291.1 \mathrm{eV}$ but also $\mathrm{C} \mathrm{sp}{ }^{3}$ components at $285.0 \mathrm{eV}(\mathrm{C}-\mathrm{C}, \mathrm{C}-\mathrm{H})$ and $286.4 \mathrm{eV}(\mathrm{C}-\mathrm{O})$ from acetone condensation process by-products at the cathode surface which does not affect the graphitic nature of the nanotubes. Still C $\mathrm{sp}^{2}$ component dominates the $\mathrm{C} 1 \mathrm{~s}$ spectrum.

\section{Mineralization of AO7 Using EF Process}

The mineralization capacity of $200 \mathrm{~mL}$ AO7 solution was monitored by measuring the TOC value of treated samples during EF treatment. The Figure 2A showed the percentage of TOC removal from initial concentration at $0.1 \mathrm{mM}$ as a function of the electrolysis time. The increase of TOC removal on both CF and
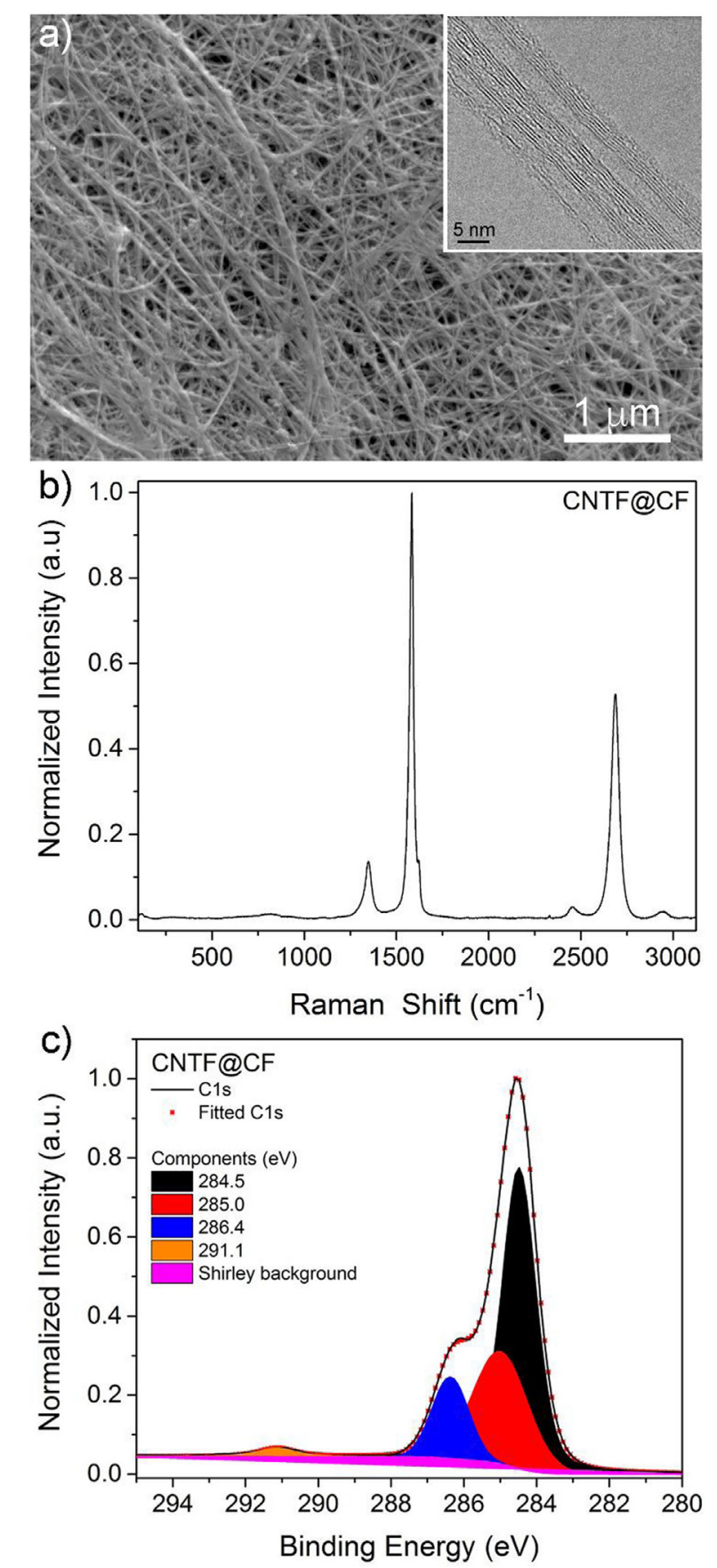

FIGURE 1 | Characterization of pristine CNTF@CF cathode. (A) SEM image showing CNTF porous structure formed by the nanotube bundles network and HRTEM image (inset) of a CNT bundle made of few-layered MWNTs. (B) Raman spectrum of highly graphitic $\left(\mathrm{I}_{\mathrm{D}} / \mathrm{I}_{\mathrm{G}} \sim 0.15\right)$. (C) X-ray photoelectron spectroscopy $\mathrm{C} 1 \mathrm{~s}$ peak with its corresponding deconvolution components assigned to graphitic CNT structure $\left(\mathrm{C}=\mathrm{C}\right.$ at $284.5 \mathrm{eV}$ and $\pi-\pi^{\star}$ band at $291.1 \mathrm{eV}$ ) and to acetone by-products (C-C and C-H at $285.0 \mathrm{eV}$ and C-O at $286.4 \mathrm{eV}$ ) as a result of the condensation process of the cathode.

CNTF@CF cathode was explained by the oxidation of AO7 and its intermediate by-products by hydroxyl radicals generated via Eq. 1 between $\mathrm{H}_{2} \mathrm{O}_{2}$ and $\mathrm{Fe}^{2+}$ catalyst. The better performance 

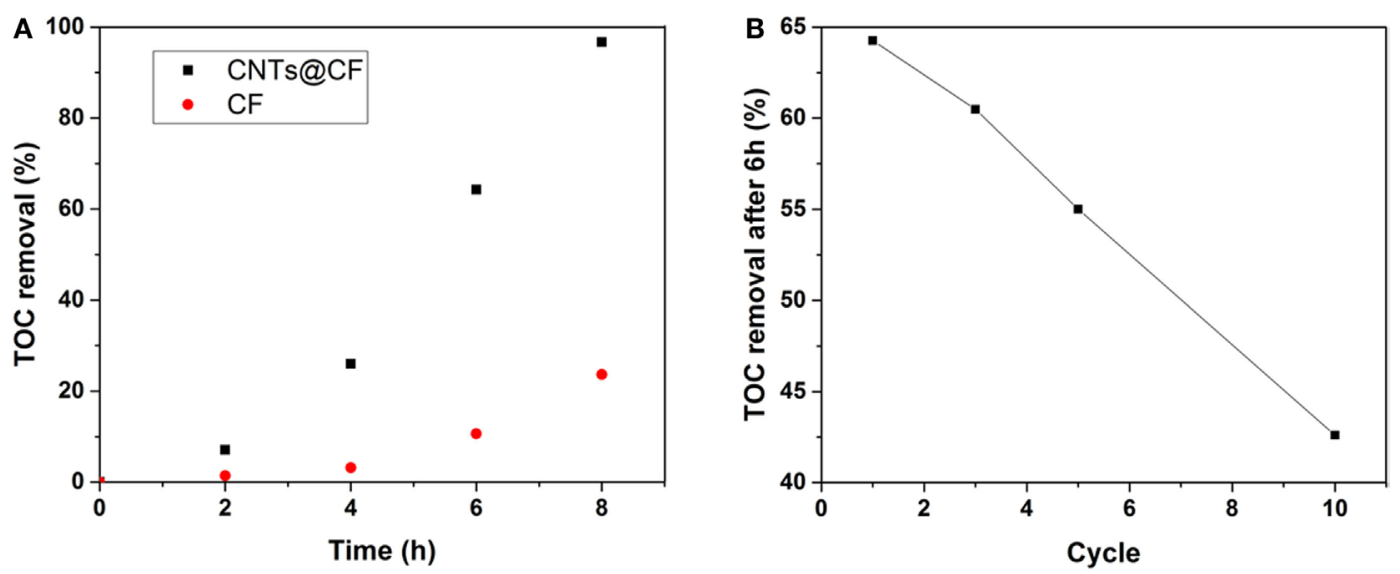

FIGURE 2 | (A) Total organic carbon (TOC) removal of $200 \mathrm{~mL}$ of $\mathrm{AO}$ aqueous solution at $0.1 \mathrm{mM}$ by electro-Fenton process with [Fe ${ }^{2+}$ ] = $0.2 \mathrm{mM}$ and $\mathrm{I}=-25 \mathrm{~mA}$. (B) The TOC removal after $6 \mathrm{~h}$ at $1,3,5$, and 10 cycles.

of CNTF@CF electrode in comparison with CF one was confirmed for all TOC values with $7.09,26,64.3$, and $96.7 \%$ at 2 , 4,6 , and $8 \mathrm{~h}$, respectively. The result proved the efficiency of application CNTs in EF process thanks to its advantages like excellent conductivity and high surface are which were well discussed in introduction part. These properties bring to many benefits for EF experiment: (i) high surface supplies more active sites for oxidation reactions happening at surface of electrode (Le et al., 2016a) and (ii) good conductivity accelerated the electron rate for more oxygen molecular reduced to $\mathrm{H}_{2} \mathrm{O}_{2}$ which is the main key to improve the performance of $\mathrm{EF}$ treatment (Le et al., 2015a). In fact, thanks to the high surface area ( $\sim 260 \mathrm{~m}^{2} / \mathrm{g}$ ) of CNTF@CF cathode, more organic dye molecular can be adsorbed and degraded in the pore structure of the fiber, leading to a quicker mineralization rate in comparison with the pristine one (Figure 2A). This CNTF high surface area has been proven to enhance charge transfer in $\mathrm{TiO}_{2}-\mathrm{CNTF}$ photoelectrodes (Moya et al., 2017). However, regarding at early electrolysis stage before $4 \mathrm{~h}$, the mineralization kinetic increased very slowly. The low rise could explained by the usual hydrophobic of CNTs hindered the access of dissolved oxygen to the surface of CNTF@CF cathode. Nevertheless, once the barriers were broken due to the vigorous stirring and continuous oxygen bubbling improving gradually the hydrophilicity of CNTs, the TOC decay increased significantly. It led to the total mineralization at the end of electrolysis on CNTF@CF cathode, while there was only $23.7 \%$ found for CF one. Moreover, this result was actually important to conclude the friendly environmental efficiency for degradation of bio-refractory pollutants by EF process using CNTF@CF cathode. The reason is that the attack of $\mathrm{AO} 7$ by hydroxyl radical will generate intermediate compounds more toxic than the parent molecule like 2-naphthol, 1,2-naphthoquinone at the beginning stage of the electrolysis when TOC removal achieves lower 30\% (Le et al., 2016b). After that, the next decomposition of aromatic by-products forms other low toxic compounds as aliphatic compounds. When TOC removal reached to over $90 \%$, the toxicity of solution will be disappeared which was strongly confirmed in previous study about the correlation between degradation pathway and toxicity of AO7 during EF process (Le et al., 2016b). In this study, there was 96.7\% TOC eliminated in 8-h treatment at CNTF@ CF cathode, proving the strength of our material in environment application for wastewater treatment by electrochemical advanced oxidation processes.

Concerning on the stability of material, the percentage of the TOC removal values at 6 -h electrolysis was monitored from cycle 1 to cycle 10. As can be seen from Figure 2B, the mineralization of AO7 slightly went down corresponding to the rise of using cycles. At the first time, there was nearly $64.3 \%$ organic carbon was decomposed, and then the CNTF@CF cathode missed around $10 \%$ its efficiency at fifth round. The AO7 degradation efficiency at $6 \mathrm{~h}$ still maintained over $40 \%$ during 10 times runs. Analyzing the CNTF@CF cathode after a long experimental period (10 cycles), its surface presents residual agglomerates of the EF process with diameter range of 70-200 nm homogeneously distributed over the CNT bundle network (Figure 3A). Raman spectrum of the 10-cycle cathode (Figure 3B) shows a ratio of $I_{D} / I_{G}$ of 0.3 which is within the range observed for the as-made material. XPS C1s spectrum (Figure 3C) also shows the preservation of the graphitic nature of the cathode with a new low intense and broad component (FWHM of $2.5 \mathrm{eV}$ ) centered at $288.5 \mathrm{eV}$ which is normally attributed to carbon-oxygen species $(\mathrm{C}-\mathrm{O}$ and $\mathrm{O}-\mathrm{C}=\mathrm{O}$ ) that could contribute to the increase of $I_{D} / I_{G}$ in the Raman spectrum. XPS survey of the 10 cycles cathode shows a higher contribution of $\mathrm{Fe}$ at its surface than pristine cathode (Figure 3D). The increased Fe amount can effect negatively the AO7 degradation, because the destruction of hydroxyl radical, as main oxidizing agent, via its reaction with excess iron catalyst as common phenomenon in EF process (Panizza and Oturan, 2011). In addition, Fe catalysts nanoparticles are encapsulated by graphitic layers, so they would only contribute to the process once these layers have been degraded. Although $\mathrm{Fe}$ is the catalyst for both nanotube growth and EF process, the fact that catalyst nanoparticles remain inside the 
nanotube makes it very difficult to detect by XPS, therefore the Fe present in the 10 cycles cathode corresponds to the EF process together $\mathrm{N}$ which is present in the AO7 aqueous solution. Based on these results, CNTF@CF structural and chemical properties are not significantly modified after long experimental periods so the loss of efficiency of the CNTF@CF is more likely to be
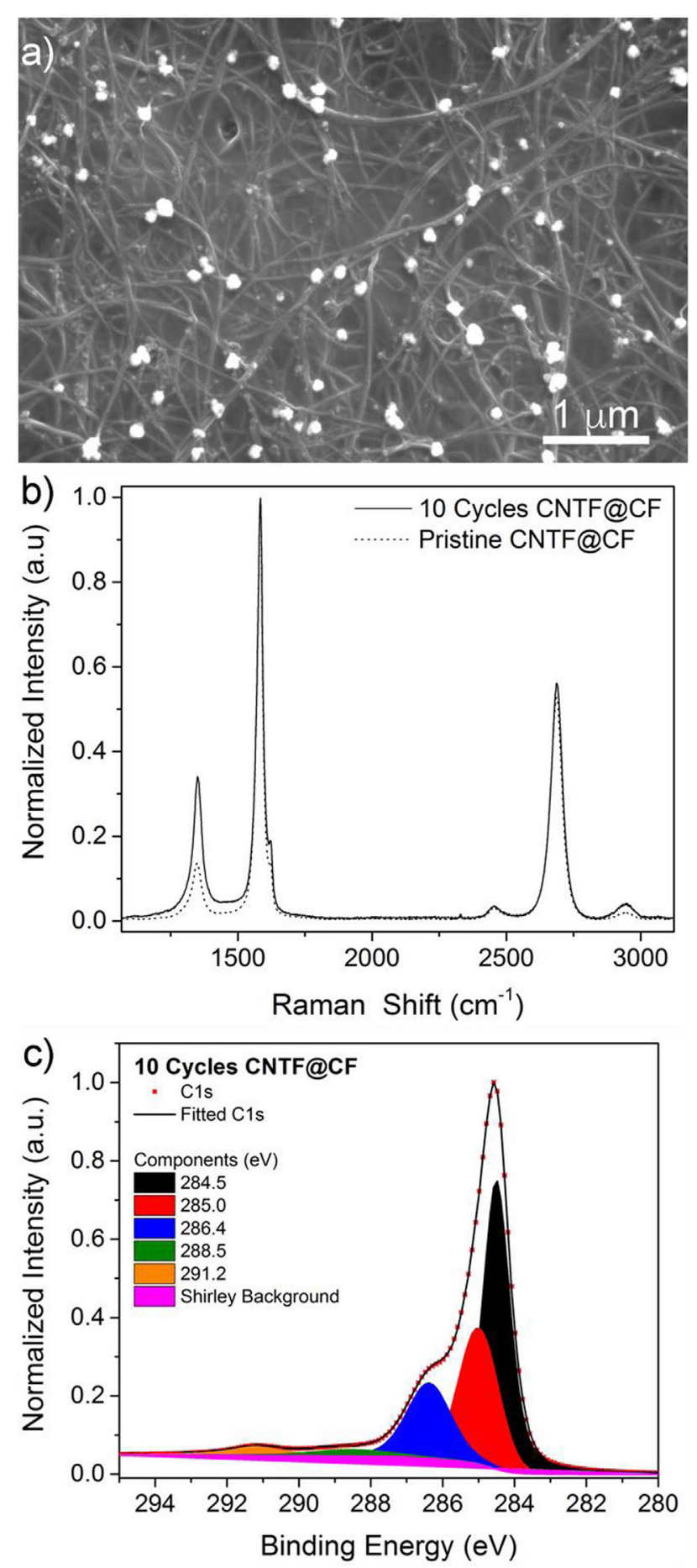

FIGURE 3 | Continued

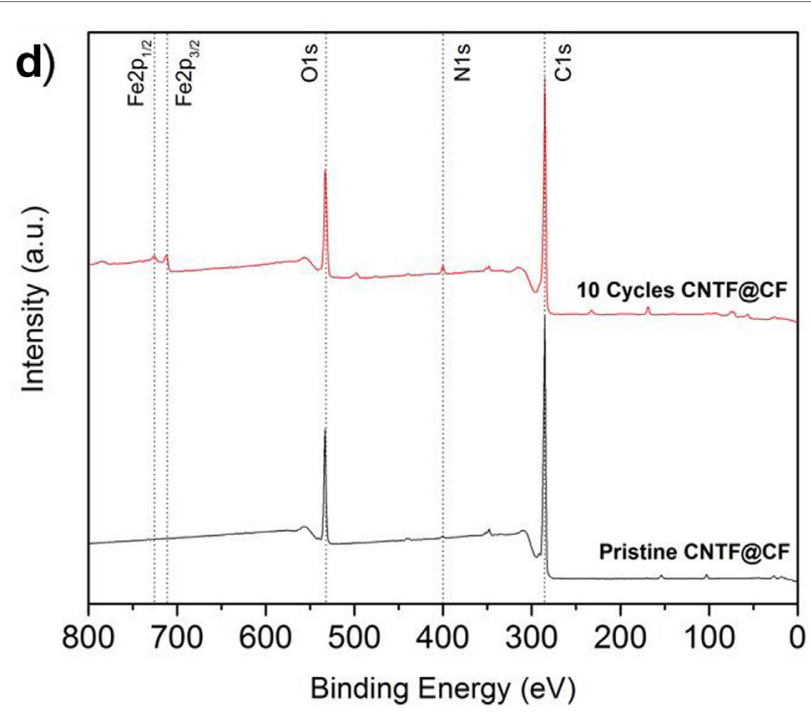

FIGURE 3 | Characterization of CNTF@CF cathode after long experimental period (10 cycles). (A) SEM image showing residual agglomerates homogenously distributed over the nanotube bundles network. (B) Raman spectrum compared to pristine cathode showing a slight increase of $I_{D} / I_{G}$ to 0.3. (C) X-ray photoelectron spectroscopy (XPS) C1s peak showing a new low intense and broad component centered at $288.5 \mathrm{eV}$ which is normally attributed to carbon-oxygen species (C-O and $\mathrm{O}-\mathrm{C}=\mathrm{O})$. (D) XPS survey showing the appearance Fe related to electro-Fenton process as well as $\mathrm{N}$ present in the $\mathrm{AO} 7$ aqueous solution.

induced by the presence of the residual agglomerates in the cathode surface that could increase the charge-transfer process resistance in the cathode. According to these results, CNTF@ CF exposed good potential as a cathodic material for EF process with high electrochemical reaction activation and reusability, which is suitable for industrial application.

\section{CONCLUSION}

The CNTF@CF was fabricated for the first time as cathodic material to remove the azo dye (AO7) by EF treatment from acid aqueous solution. CNTF@CF cathode is produced by the direct spinning of $\mathrm{mm}$-long CNTs grown by floating catalyst CVD process at $1,250^{\circ} \mathrm{C}$ on a carbon fiber substrate. CNTF@ CF cathode presents high surface area $\left(\sim 260 \mathrm{~m}^{2} / \mathrm{g}\right)$ which enhances the charge transfer process during mineralization of AO7 solution. The hydroxyl radical as main oxidizing agent in situ produced via Fenton reaction by combination of soluble $\mathrm{Fe}^{2+}$ catalyst at $0.2 \mathrm{mM}$ and $\mathrm{H}_{2} \mathrm{O}_{2}$ generated from oxygen reduction. The deposition of CNTs on the surface of CF improved significant the mineralization efficiency by confirming on TOC removal from initial solution. Oxidative decomposition of AO7 during EF process led to the complete mineralization after $8 \mathrm{~h}$ with TOC decay percentage found to be $96.7 \%$. This value was $73 \%$ higher than on CF support at the same electrolysis time. In addition, the stability of material was investigated basing on TOC measurement at $6 \mathrm{~h}$. Characterization of the cathode before and after long period experiment proved that 
the graphitic nature of the cathode is not significantly modified by EF process while the formation of 70-200 nm agglomerates during the long treatment could be related to the $10 \%$ loss of efficiency after five cycles. The CNTF@CF cathode proved its good reusability when only $10 \%$ of mineralization efficiency declined after five cycles.

\section{AUTHOR CONTRIBUTIONS}

The contribution of TL is electrochemistry and material electrodes devoted to electrochemical advanced oxidation processes (EAOPs). BA and JV are experts in material science and more especially multifunctional nanocomposites. They focused here on the synthesis of carbon nanotube fiber by direct spinning of

\section{REFERENCES}

Aaron, J. J., and Oturan, M. A. (2001). New photochemical and electrochemical methods for the degradation of pesticides in aqueous media. Environmental applications. Turk. J. Chem. 25, 509-520.

Brillas, E., Sirés, I., and Oturan, M. A. (2009). Electro-Fenton process and related electrochemical technologies based on Fenton's reaction chemistry. Chem. Rev. 109, 6570-6631. doi:10.1021/cr900136g

Dresselhaus, M. S., Dresselhaus, G., Saito, R., and Jorio, A. (2005). Raman spectroscopy of carbon nanotubes. Phys. Rep. 409, 47-99. doi:10.1016/j.physrep. 2004.10.006

Le, T. X. H., Bechelany, M., Champavert, J., and Cretin, M. (2015a). A highly active based graphene cathode for the electro-Fenton reaction. RSC Adv. 5, 42536-42539. doi:10.1039/C5RA04811G

Le, T. X. H., Bechelany, M., Lacour, S., Oturan, N., Oturan, M. A., and Cretin, M. (2015b). High removal efficiency of dye pollutants by electron-Fenton process using a graphene based cathode. Carbon N. Y. 94, 1003-1011. doi:10.1016/j. carbon.2015.07.086

Le, T. X. H., Charmette, C., Bechelany, M., and Cretin, M. (2016a). Facile preparation of porous carbon cathode to eliminate paracetamol in aqueous medium using electro-Fenton system. Electrochim. Acta 188, 378-384. doi:10.1016/j. electacta.2015.12.005

Le, T. X. H., Nguyen, T. V., Yacouba, Z. A., Zoungrana, L., Avril, F., Petit, E., et al. (2016b). Toxicity removal assessments related to degradation pathways of azo dyes: toward an optimization of electro-Fenton treatment. Chemosphere 161, 308-318. doi:10.1016/j.chemosphere.2016. 06.108

Le, T. X. H., Nguyen, T. V., Amadou Yacouba, Z., Zoungrana, L., Avril, F., Nguyen, D. L., et al. (2017). Correlation between degradation pathway and toxicity of acetaminophen and its by-products by using the electroFenton process in aqueous media. Chemosphere 172, 1-9. doi:10.1016/j. chemosphere.2016.12.060

Li, Y.-L., Kinloch, I. A., and Windle, A. H. (2004). Direct spinning of carbon nanotube fibers from chemical vapor deposition synthesis. Science 304, 276-278. doi:10.1126/science.1094982

Martínez, S. S., and Uribe, E. V. (2012). Enhanced sonochemical degradation of azure B dye by the electroFenton process. Ultrason. Sonochem. 19, 174-178. doi:10.1016/j.ultsonch.2011.05.013

Moya, A., Kemnade, N., Osorio, M. R., Cherevan, A. S., Granados, D., Eder, D., et al. (2017). Large area photoelectrodes based on hybrids of CNT fibres and ALD-grown $\mathrm{TiO}_{2}$. J. Mater. Chem. A 5, 24695-24706. doi:10.1039/ C7TA08074C millimeters long CNTs from the gas phase by floating catalyst CVD. $\mathrm{MB}$ worked in material science in strong interactions with $\mathrm{BA}$ and JV to optimize cathodic material performance. MC work at the interface Material and Electrochemistry with the aim to optimize the mineralization of biorefractory pollutants by EAOP.

\section{ACKNOWLEDGMENTS}

We gratefully acknowledge financial support from the ANR project ECOTS/CELECTRON for the funding of this research. JV is grateful for generous financial support provided by the European Union Seventh Framework Program under grant agreement 678565 (ERC-STEM).

Özcan, A., Oturan, M. A., Oturan, N., and Şahin, Y. (2009). Removal of acid orange 7 from water by electrochemically generated Fenton's reagent. J. Hazard. Mater. 163, 1213-1220. doi:10.1016/j.jhazmat.2008.07.088

Özcan, A., Şahin, Y., Koparal, A. S., and Oturan, M. A. (2008). Carbon sponge as a new cathode material for the electro-Fenton process: comparison with carbon felt cathode and application to degradation of synthetic dye basic blue 3 in aqueous medium. J. Electroanal. Chem. 616, 71-78. doi:10.1016/j. jelechem.2008.01.002

Panizza, M., and Oturan, M. A. (2011). Degradation of alizarin red by electroFenton process using a graphite-felt cathode. Electrochim. Acta 56, 7084-7087. doi:10.1016/j.electacta.2011.05.105

Reguero, V., Alemán, B., Mas, B., and Vilatela, J. J. (2014). Controlling carbon nanotube type in macroscopic fibers synthesized by the direct spinning process. Chem. Mater. 26, 3550-3557. doi:10.1021/cm501187x

Sirés, I., Garrido, J. A., Rodríguez, R. M., Brillas, E., Oturan, N., and Oturan, M. A. (2007). Catalytic behavior of the $\mathrm{Fe}^{3+} / \mathrm{Fe}^{2+}$ system in the electro-Fenton degradation of the antimicrobial chlorophene. Appl. Catal. B 72, 382-394. doi:10.1016/j.apcatb.2006.11.016

Vilatela, J. J., and Marcilla, R. (2015). Tough electrodes: carbon nanotube fibers as the ultimate current collectors/active material for energy management devices. Chem. Mater. 27, 6901-6917. doi:10.1021/acs.chemmater.5b02783

Wang, A., Qu, J., Ru, J., Liu, H., and Ge, J. (2005). Mineralization of an azo dye acid red 14 by electro-Fenton's reagent using an activated carbon fiber cathode. Dyes Pigm. 65, 227-233. doi:10.1016/j.dyepig.2004.07.019

Wang, C.-T., Hu, J.-L., Chou, W.-L., and Ku, Y.-M. (2008). Removal of color from real dyeing wastewater by electro-Fenton technology using a threedimensional graphite cathode. J. Hazard Mater. 152, 601-606. doi:10.1016/j. jhazmat.2007.07.023

Yue, H., Reguero, V., Senokos, E., Monreal-Bernal, A., Mas, B., Fernández-Blázquez, J. P., et al. (2017). Fractal carbon nanotube fibers with mesoporous crystalline structure. Carbon N. Y. 122, 47-53. doi:10.1016/j.carbon.2017.06.032

Conflict of Interest Statement: The authors declare that the research was conducted in the absence of any commercial or financial relationships that could be construed as a potential conflict of interest.

Copyright (c) 2018 Huong Le, Alemán, Vilatela, Bechelany and Cretin. This is an open-access article distributed under the terms of the Creative Commons Attribution License (CC BY). The use, distribution or reproduction in other forums is permitted, provided the original author(s) and the copyright owner are credited and that the original publication in this journal is cited, in accordance with accepted academic practice. No use, distribution or reproduction is permitted which does not comply with these terms. 